\title{
Minimization of Losses in Permanent Magnet Synchronous Motors Using Neural Network
}

\author{
Mona N. Eskander \\ Power Electronics and Energy Conversion Dept. \\ Electronics Research Institute \\ Cairo, Egypt
}

\begin{abstract}
In this paper. maximum efficiency operation of tro types of permanent magnet synchronous machine drives. namcly: surface type permanent magnet synchronous machine (SPMSM) and interior type permanent magnet synchronous machine (IPMSM), are investigated. The efficiency of both drives is maximized by minimizing cupper and iron losses. Loss minimization is implemented using flux weakening. A neural network controller (NNC) is designed for each drive. to achieve loss minimization at different speed and load values. Data for training the NNC are obtained through off-line simulations of SPMSM and IPMSM at different operating conditions. The accuracy and fast response of each of the NNC is proved by applying sudden changes in speed and load and tracking the NNC output. The drives' efficiency obtained by flux weakening is compared with the efficiency obtained when setting the d-axis current component to zero. while varying the angle of advance " $p$ " of the PWM inverter supplying the PMSM drive. $\mathrm{A} N \mathrm{~N}$ is also designed, and trained to vary $\varphi$ following the derived control law. The accuracy and fast response of the NN controller is also proved.
\end{abstract}

\section{Introduction}

The Permanent magnet synchronous motors PMSM offers several advantages. namely; a high torque-toinertia ratio and an cxcellent power factor, since the copper losses are confined to the stator. In addition. for the same delivered mechanical power. a PMSM needs a smaller line current value. which is favorable for the design of the electronic power converter feeding this drive. However, the need to save energy still exists to develop an efficient drive. Several control methods have been proposed to minimize the losses of PMSM drives $[1-7]$

In the previous work. no attempt was done to apply Neural Network (NN) controllers for maximum efficiency operation of PMSM drive. In this paper. a loss minimization strategy is developed to minimize copper and iron losses in e (SPMSM), and (IPMSM) drives. The proposed strategy is based on the air-gap flux weakening, where the value of the d-axis stator current component that leads to minimum losses is first derived for IPMSM and SPMSM drives. To achieve fast response with minimum losses within wide speed range. flux weakening is implemented using neural networks $(\mathrm{NN})$. The advantages of the $\mathrm{NN}$ lie in its learning character, as well as in its ability to deal with nonlinearities. Also the efficiency of the PMSM drive is deduced when setting the d-axis stator current component to zero while varying the angle of advance " $\alpha$ " of the PWM inverter supplying the PMSM drive. The value of $\alpha$ that allows maximum efficiency is derived as function of speed and load, and a NN controller is designed and tested to implement this scheme

\section{Loss Minimization Model of Interior PMSM}

The steady state model of the IPMSM is derived from the $d$ and q-axes per-phase equivalent circuit shown in Fig. (1):

$V_{4}=R_{s} i_{q}+()_{s} L_{d} i_{o d}+()_{s} \lambda$

$V_{d}=R_{s} i_{d}-(1)_{s} L_{q} i_{o q}$

The electric torque is given by:

$T_{e}=1.5 \mathrm{P}\left[i_{\gamma} \mathrm{i}_{o q}+\left(\mathrm{L}_{\mathrm{d}}-\mathrm{L}_{\mathrm{q}}\right) \mathrm{i}_{\mathrm{od}} \mathrm{i}_{\mathrm{oq}}\right]$

And the equation for motor dynamics is:

$T_{e}=T_{L}+B *\left(\omega_{r}+J * p()_{r}\right.$

The main losses of the PMSM are the copper and iron losses. Referring to the general equivalent circuit of the PMSM given in Fig.(1), the copper losses are given by

$P_{c u}=R_{s} \cdot i_{d}+R_{s} i_{q}^{2}$

While the iron losses are given by

$P_{\mathrm{fe}}=(1){ }_{\mathrm{s}} * \hat{\gamma}_{\mathrm{c}}^{2} \cdot d \mathrm{R}_{\mathrm{c}}$

Where. $\lambda_{0}$ is the air gap flux.

Eq. (6) could be written as:

$P_{\mathrm{fe}}=\omega^{2}{ }^{*} *\left[\left(\hat{i}_{\mathrm{o}}+\mathrm{L}_{\mathrm{d}} \mathrm{i}_{\mathrm{od}}\right)^{2}+\left(\mathrm{L}_{\mathrm{q}} \mathrm{i}_{\mathrm{oq}}\right)^{2}\right] / \mathrm{R}_{\mathrm{c}}$

Adding equations (5) and (7), and

differentiating with respect to $i_{\text {od }}$, gives:

$\partial \mathrm{P}_{\mathrm{L}} / \hat{C}_{\mathrm{id}}=\mathrm{i}_{o d}\left[\mathrm{R}_{\mathrm{s}}+\left(\omega^{2}{ }_{\mathrm{s}} * \mathrm{~L}_{\mathrm{d}}{ }_{\mathrm{d}} / \mathrm{R}_{\mathrm{c}}\right)\right]$

$\left.+\mathrm{i}_{\mathrm{oq}} * \partial \mathrm{i}_{\mathrm{oq}} / \mathrm{Cid}_{\mathrm{od}}\left[\mathrm{R}_{\mathrm{s}}+\left(\omega_{\mathrm{s}}{ }_{\mathrm{s}}^{*} \mathrm{~L}_{\mathrm{q}}^{2} / \mathrm{R}_{\mathrm{c}}\right)\right]+\left(\omega^{2}{ }_{\mathrm{s}}^{*} \lambda^{*} \mathrm{~L}_{\mathrm{d}} / \mathrm{R}_{\mathrm{c}}\right)\right]$

From the electric torque equation (3), the current $i_{o q}$ is:

$\mathrm{i}_{\mathrm{oq}}=\mathrm{T}_{\mathrm{e}} / 1.5^{*} \mathrm{P}\left[\lambda+\left(\mathrm{L}_{\mathrm{d}}-\mathrm{L}_{\mathrm{q}}\right) \mathrm{i}_{\mathrm{od}}\right]$

Hence $C \mathrm{i}_{\mathrm{oq}} / \partial \mathrm{i}_{\mathrm{od}}$ is derived as:

$\partial \mathrm{i}_{o q} / \partial \mathrm{i}_{o d}=-\left[\left(\mathrm{L}_{d}-\mathrm{L}_{\mathrm{q}}\right) * \mathrm{~T}_{\mathrm{e}} / 1.5 * \mathrm{P}\left[\lambda+\left(\mathrm{L}_{\mathrm{d}}-\mathrm{L}_{\mathrm{q}}\right) \mathrm{i}_{\mathrm{od}}\right]^{2}\right.$ 
Substituting.(10) into.(8) and equating the result to zero. gives the optimum $d$-axis stator current $i_{\text {dop }}$ that leads to minimum losses at a given steady state speed and torque:

$$
\begin{aligned}
& i_{d o p}=1.5 P^{*} L^{*}\left\{\left[\left(R_{s} * R_{c}\right)+\left(\omega_{s}^{2} * L_{q}^{2}\right)\right] /\left(\left(R_{s} * R_{c}+\omega^{2}\right.\right.\right. \\
& \left.\left.\mathrm{L}_{\mathrm{d}}^{2}\right) \mid\right\}_{\mathrm{ou}}^{3} \\
& -\left\{\mid \lambda^{*}\left(\omega^{2}{ }_{s}^{*} L^{2} d|/| R_{s} * R_{c}+\omega_{s}^{2} L_{d}^{2} \mid\right\}\right.
\end{aligned}
$$

Loss minimization condition for voltage controlled schemes is obtained by substituting eq.(11) into equations (1) and (2) and using the supply voltage $V_{s}$ as:

$V_{s}=\sqrt{ }\left(V^{2}{ }_{d}+V^{2}{ }_{q}\right)$

To prove the existence of minimum losses as speed varies, the total losses are plotted versus $V_{s}$ at variable speed and constant torque in Fig.(2).

\section{Network Controller for Loss-Minimization in IPMSM}

\subsection{Control Scheme}

The control scheme to implement loss minimization in IPMSM is shown in Fig. (3). In such scheme, a PI controller is used to calculate $i_{q}$ from the difference between the torque command and the actual torque. The inputs to the proposed $N N$ are $i_{q}^{*}$ and the rotor speed $\omega_{1}$. The output of the NN is $i_{\text {dop }}$, which is used with $i_{q}^{*}$ to calculate the 3-phase currents, in current controlled schemes, or the 3-phase voltages in the voltagecontrolled scheme.

\subsection{Neural Network (NNI) Controller for IPMSM}

In order to establish the neural network model, the interconnected weights and biases are trained according to an existing input/output pattern. This pattern is obtained from the simulation results of the described loss minimization control strategy, i.e. off- line training. After many trials, a 3-layer NN with two input neurons. 2- hidden layer neurons, and one output neuron gave the required error goal after few epochs. The trained output of $\mathrm{NNI}$ is compared with $\mathrm{i}_{\text {dop }}$ calculated from the condition of minimum losses, and the results given in Fig.(4) as function of rotor speed. The slight difference between the two values of current proves the accurate tracking of the current value required for loss minimization.

In order to verify the fast response of the established NNI loss minimization controller, sudden step change in the drive speed is imposed at constant load torque, and the calculated power loss at this operating point is plotted versus time in Fig.(5a), while the existing power loss after applying NNI controller is plotted in Fig.(5b) for clarity. The corresponding fast change in the oulput of NNI as the speed changes proves the fast response of the neural network output, which assures that minimum losses are obtained at different operating conditions. This fact is further proved by applying a step change of load torque and plotting the expected power loss with that obtained after applying NNI.
Results shown in Fig.(6) assures the fast response of the designed NNI.

\section{Loss Minimization Model of Surface SPMSM}

In the case of SPMSM drive, $\mathrm{L}_{d}=\mathrm{L}_{q}=\mathrm{L}_{s}$, where $\mathrm{L}_{s}$ is the stator inductance. Hence, the iron loss equation (7) reduces to

$\mathrm{P}_{\mathrm{fe}}=\omega^{2}{ }_{\mathrm{s}} *\left[\left(\lambda+\mathrm{L}_{\mathrm{s}} \mathrm{i}_{\mathrm{od}}\right)^{2}+\left(\mathrm{L}_{\mathrm{s}} \mathrm{i}_{\mathrm{oq}}\right)^{2}\right] / \mathrm{R}_{\mathrm{c}}$

and the electric torque reduces to:

$T_{e}=1.5 P \lambda i_{\text {oq }}$

Adding cupper and iron losses and differe respect to $i_{\text {od }}$ gives:

$\partial P_{L} / \partial i_{o d}=R_{s} \cdot i_{o d}+\left(L_{s} \omega^{2}{ }_{s} \lambda\right) / R_{c}+\left(\omega_{s}^{2} L^{2} i_{\text {od }}\right) R_{c}$

(15)

Equating (15) to zero leads to the following expression for the optimum d-axis current at a given speed and torque:

$i_{\text {dop }}=\left(L_{s} \omega_{s}^{2} \lambda\right) /\left(R_{s} \cdot R_{c}+\omega_{s}^{2} L_{s}^{2}\right)$

\section{Neural Network Controller for Loss- Minimization in SPMSM}

\subsection{Control Scheme}

Due to the simpler expression for optimal d-axis current given in (16), and the independency of $i_{\text {dop }}$ on th q-axis current component, the PI controller used with IPMSM drive is canceled. Instead the qaxis current is directly calculated from the command torque, which is used as one of the inputs of the neural network controller for SPMSM drive (NNS).

\subsection{Neural Network (NNS) Description}

An off line trained neural network NNS is designed for loss minimization in SPMSM. The inputs to the NNS are the drive speed, and the load torque (which determines the $q$-axis component of the stator current). The output of the network is the optimal value of d-component of stator current $i_{d u p}$. The input/output pattern used to train NNS is obtained from the simulation results of the described loss minimization control strategy. A 3layer NN with two input neurons, 2- hidden layer neurons, and one output neuron gave the required error goal after few epochs. The trained output of NNS is compared with $i_{\text {dop }}$ calculated from the condition of minimum losses, and the results given in Fig.(7) as function of rotor speed. The slight difference between the two values of current proves the accurate tracking of the current value required for loss minimization.

In order to verify the fast response of the established NNS loss minimization controller, a step change of load torque is applied to the SPMSM, and NNS output current plotted in Fig.(8). Results prove the fast response of the designed NNI. This fact is further proved by applying a sudden step change of $30 \mathrm{rad} / \mathrm{sec}$ to the speed command at constant load torque, and NNS 
output plotted versus time in Fig.(9), The corresponding fast change in the output of NNS as the speed changes proves the fast response of the neural network output, which assures that minimum losses are obtained at different operating conditions.

\section{Operation At $i_{d}=0$}

\subsection{Equation Derivation}

The d-component of the stator current is set to zero, and another approach is used to allow the PMSM to operate with minimum winding losses. This approach depends on variation of the inverter angle as the speed and load varies 10 achieve minimum losses. To determine this optimum angle in an analytical manner, id is set to zero in equations (1)-(3) leading to the following voltage and torque equations:

$\mathrm{V}_{\mathrm{q}}=\mathrm{V}_{\mathrm{i}} \cos \varphi=\mathrm{R}_{\mathrm{s}} \cdot \mathrm{i}_{\mathrm{oq}}+\omega_{\mathrm{s}} \lambda$

$V_{d}-V_{1} \sin \left(\sin =-(1)_{s} L i_{\text {oq }}\right.$

The electric torque is given by:

$\left.T_{0}=1.5 P\right\rangle_{104}$

Where L

$=\mathrm{Lq}$ for IPMSM drive, and $\mathrm{L}=\mathrm{Ls}$ for SPMSM drive

It is clear that with this constraint and for steady state operation at a required load torque, the quadrature axis current can be calculated from (19), and used to optimize the inverter angle. From (17) and (18):

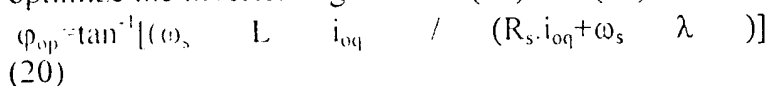

To prove the effect of the inverter angle of advance on the drive efficiency, the efficiency and electric torque for $\varphi=0$, and for $\varphi=\varphi_{\text {op }}$ are plotted versus speed in Fig.(9). Results show that a much higher torque and a higher efficiency is obtained when $\varphi$ is varied with speed to follow the values of $\varphi_{\text {op }}$

\subsection{Comparison Between Maximum Efficiency Operation Schemes}

A comparison is done between the values of efficiency obtained by flux weakening technique, and that obtained by varying the inverter angle of advance in SPMSM. Figure (11) shows the electric torque and efficiency with loss minimization scheme ( $\mathrm{Tel}$ and effl), and electric torque and efficiency for optimum inverter angle operation ( $\mathrm{Te} 2$ and eff 2 ). It is concluded that while the efficiencies are nearly equal, the electric torque is slightly higher for the case of optimum inverter angle operation. Therefore, since the two investigated techniques for maximum efficiency operation gave same results, setting the $d$-axis current component to zero while varying the optimum angle of advance might be more economic to implement, and more safe from the point of view of magnet demagnetization. Flux weakening is better used for high speed operation of PMSM drives.

\subsection{Neural Network Implementation}

For fast and robust application of optimum inverter angle at all operating speed range, an off line trained neural network NNA is designed, and is applicable for both SPMSM and IPMSM drives. The inputs to the NNA are the drive speed, and the load torque (which determines the $q$-axis component of the stator current). The output of the network is the optimal value of the inverter angle of advance $\varphi_{\text {dop }}$. The input/output pattern used to train NNA is obtained from the simulation results given in the previous section. A 3layer $\mathrm{NN}$ with two input neurons, 2- hidden layer neurons, and one output neuron gave the required error goal after few epochs.

In order to verify the fast response of the established NNA maximum efficiency controller,. a step change of 0.2 N.m.in load torque is applied to the SPMSM, and NNA output (optimum inverter angle), as well as the calculated inverter angle are plotted in Fig.(12). Results proves the fast response of the designed NNA.

\section{Conclusion}

In this paper, efficiency of two types of permanent magnet synchronous machine drives, namely; surface type permanent magnet synchronous machine (SPMSM) and interior type permanent magnet synchronous machine (IPMSM), are investigated is maximized by minimizing cupper and iron losses. Loss minimization is implemented using flux weakening. A neural network controller (NNC) is designed for each drive, to achieve loss minimization at different speed and load values. Data for training the NNC are obtained through off-line simulations of SPMSM and IPMSM at different operating conditions. The accuracy and fast response of each of the NNC is proved by applying sudden changes in speed and load and tracking the NNC output.

Also the PMSM drives' efficiency is derived when setting the d-axis current component to zero, while varying the angle of advance " $\varphi$ " of the PWM inverter supplying the PMSM drive. A neural network NNA is also designed, and trained to vary $\varphi$ following the derived control law. The accuracy and fast response of NNA controller is also proved.

Comparison is done between the drive efficiency obtained with flux weakening, and the drive efficiency obtained with the conventional " $i_{d}=0$ control". Results proved that the two methods lead to equal efficiencies. This result are in favor of the " $i_{d}=0$ control", since less control circuits are needed for its implementation. Also it prevents magnet demagnetization that may occur due to any maloperation of the control system.

\section{References}

1. J.C.Andreas, "Energy Efficient Electric Motors", New york; Marcel Dekker, 1992.

2. S. Morimoto, Y. Tong, Y. Takeda, and T. Hirasa, "Loss Minimization Control of Permanent Magnet Synchronous Motor 
Drives", IEEE Trans. on Industrial Electronics, vol.41, October 1994, pp511-517.

3. Y. Nakamura, T. Kudo, F. Ishibashi, and S. Hibino, "High Efficiency Drive Due to Power Factor Control of a Permanent Magnet Synchronous Motor", IEEE Trans. Power Electronics, vol.10, March 1995, pp247-253.

4. C.Chan, R. Zhang, K. Chau, and J. Jiang, "Optimal Efficiency Control of PM Hybrid Motor Drives for Electrical Vehicles", Proc. II:EE PESC'97, vol.1, June 1997, pp363-368.

$\therefore$ (. Mademlis, J. Xypteras, and N.Margaris, "Loss Minimization in Surface Permanent Magnet Synchronous Motor Drives", IEEE Trans. on Industrial Electronics, vol.47, February 2000, pp 115-122.

6. P. Krause, R. Nucera, R. Krefta, and $O$. Wasynczuk, "Analysis of a Permanent Magnet Synchronous Machine Supplied from 1180 Inverter with Phase Control", IEEE Trans. on Energy Conversion, vool.2, No.3, September 1987, pp423-430.

7. R. Spee, and A. Wallace, "Performance Characteristics of Brushless DC Drives", IEEE Tans. On Industry Applications, vol.24, July/August 1988, pp568-573.

\section{Appendix}

(i) IPMSM parameters:

900 watt, 1700 rpm,

$\mathrm{L}_{\mathrm{d}}=0.027 \mathrm{H}$.

$\mathrm{L}_{1 \mathrm{I}}=0.067 \mathrm{II}$.

$R,=4.30 \mathrm{hm}$

$V_{\mathrm{dl}}=250 \mathrm{~V}$.

$\mathrm{P}=4$ poles.

$\lambda=0.232$ web.

(ii) SPMSM parameters

400 watt. $1700 \mathrm{rpm}$.

$R_{1}=3$ ohm

$L_{1}=0.0121 \mathrm{H}$.

$\lambda=0.083$ web

$\mathrm{P}=4$ poles

$V_{\mathrm{dc}}=100 \mathrm{~V}$
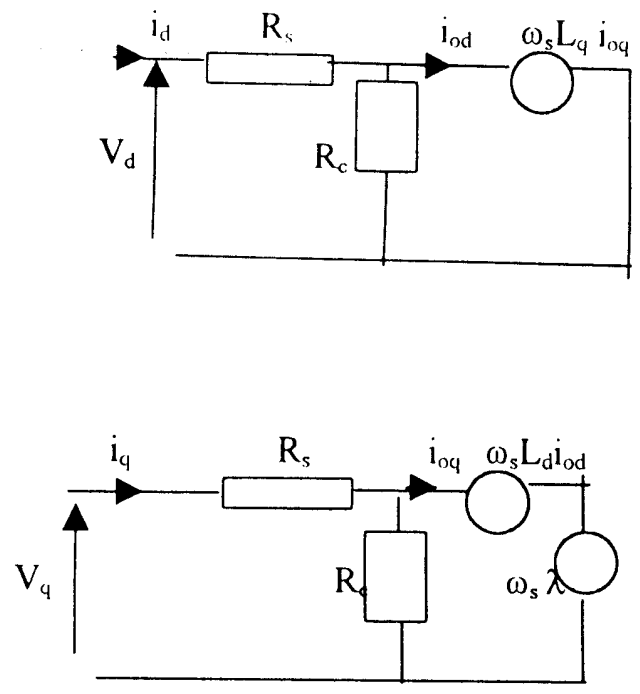

Fig.(1) Equivalent Circuit for PMSM in the d and $q$ axes

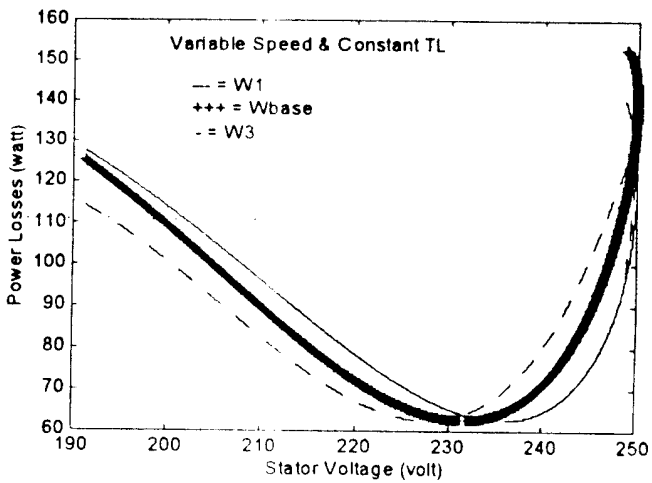

Fig.(2) Power Loss Versus Stator Voltage at Variable Specd and Constant Load 


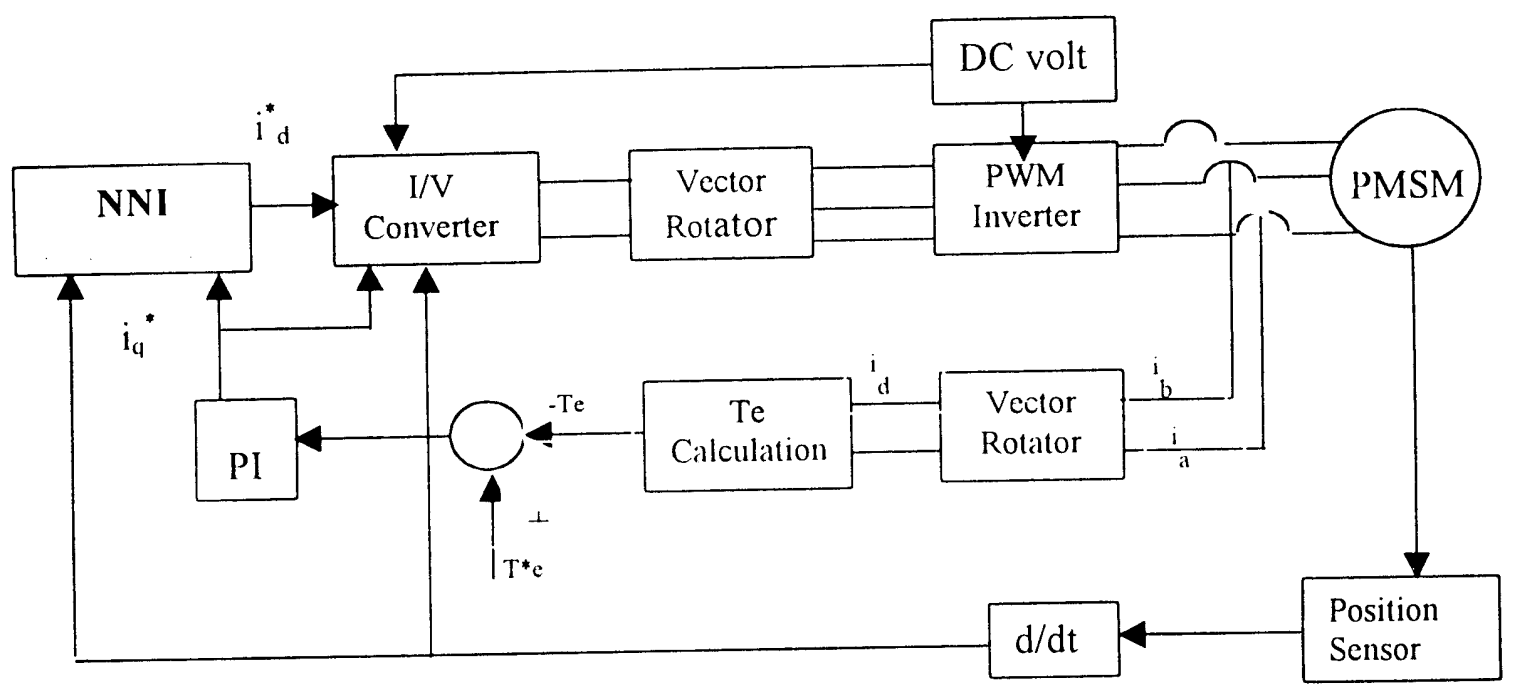

Fig.(3) Control System for Loss Minimization In IPMSM Drives

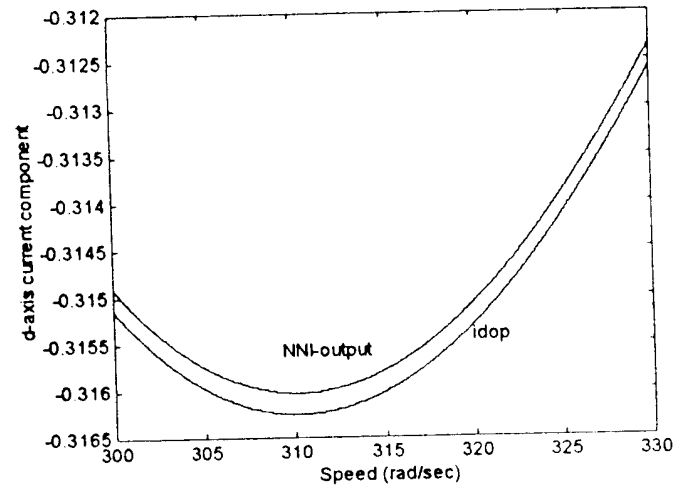

Fig.(4) Calculated \& NNI idop

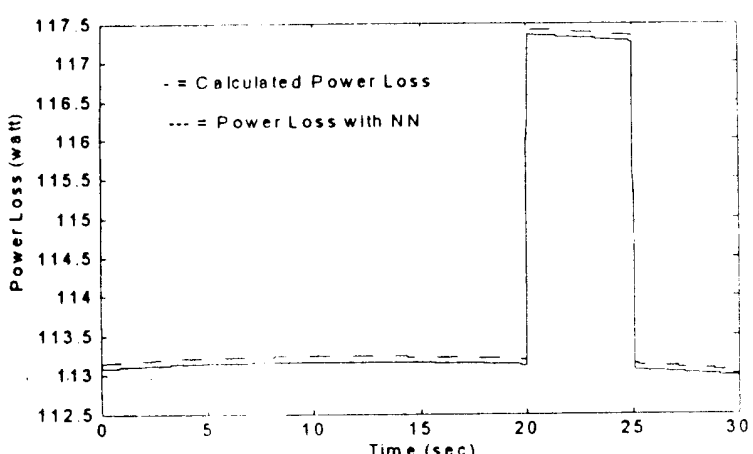

Fig.(6) Calculated and Actual Power Loss when Applying NNI at a Step Change in TL

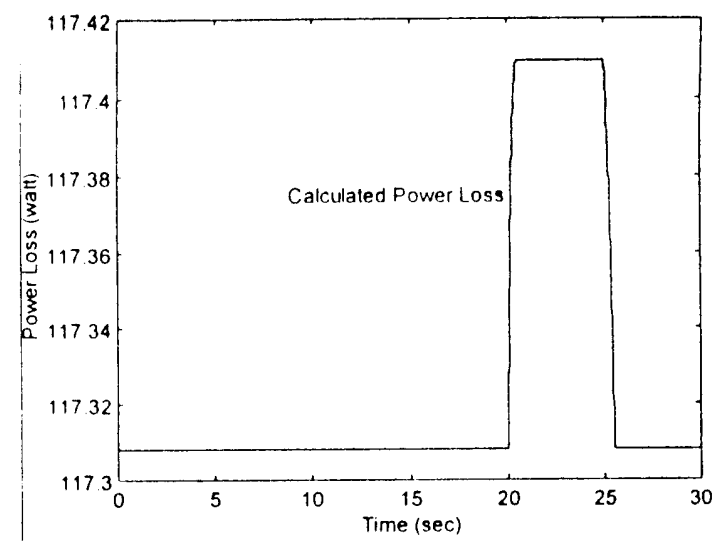

Fig. (5a) Calculated PL at Step Change in $\omega_{\text {r }}$

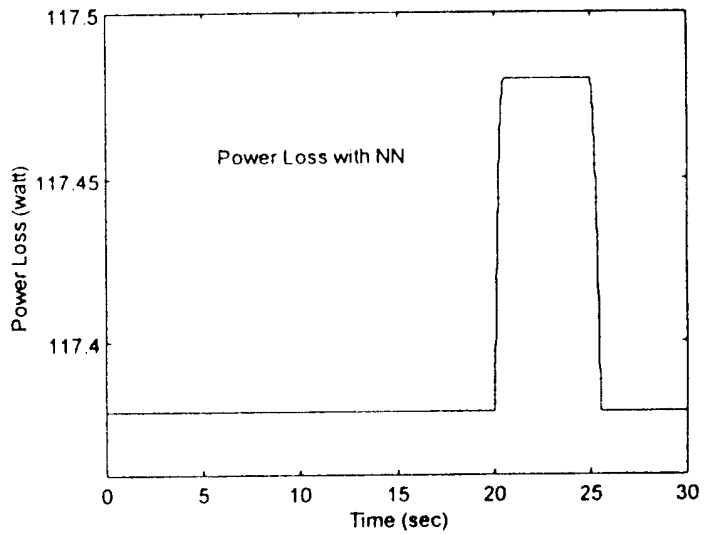

Fig. (5b) Actual PL at Step Change in $\omega_{r}$ 


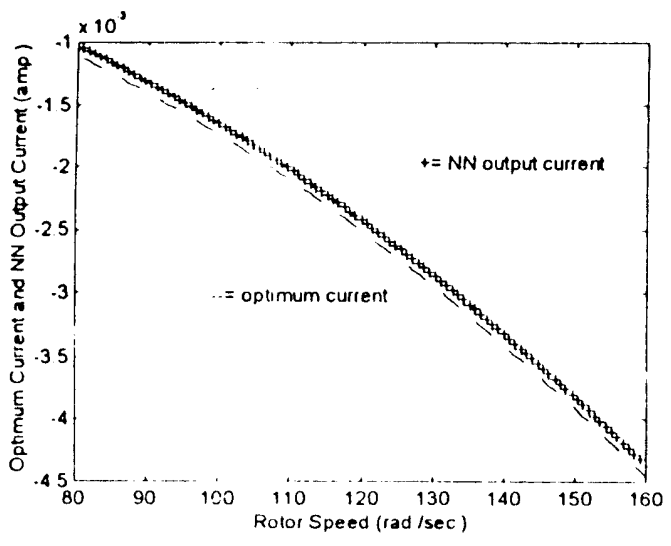

Fig.(7) NNS Output and $i_{\text {dop }}$ versus Speed

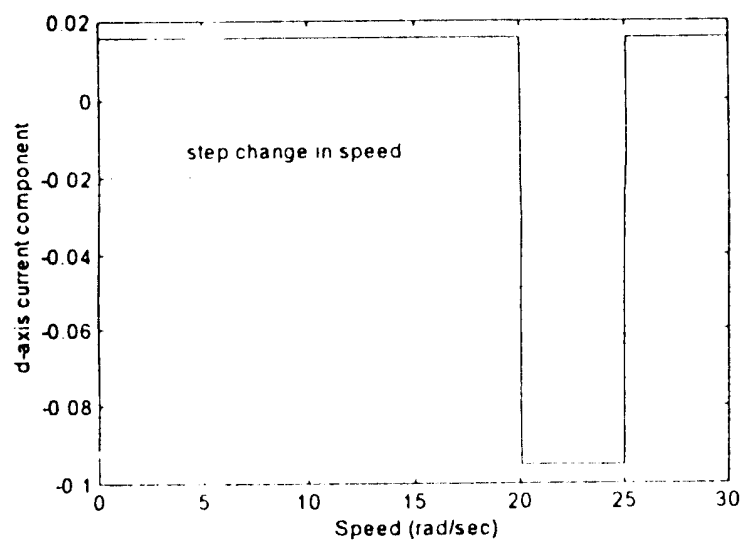

Fig.(9) NNS Output at Step Change in Speed

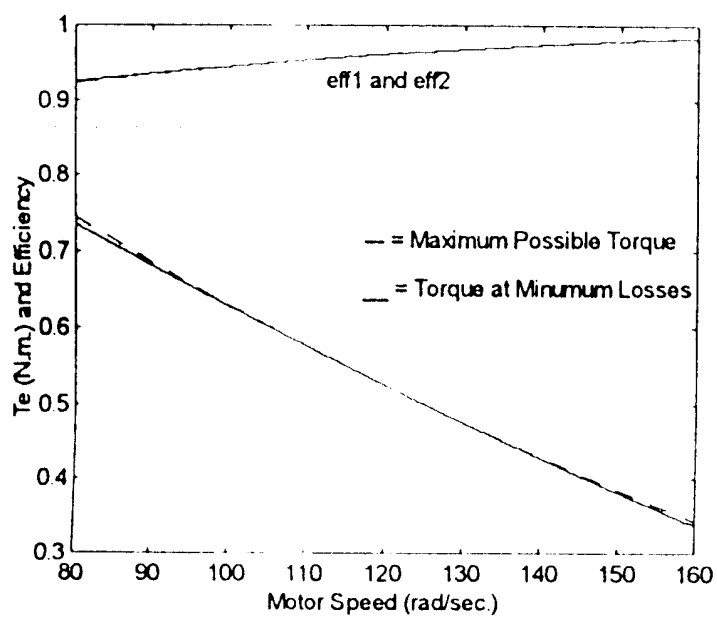

Fig. (11) Tel and effl with Loss Minimization Technique, and Te2 and eff 2 for Optimal Inverter Angle Operation'

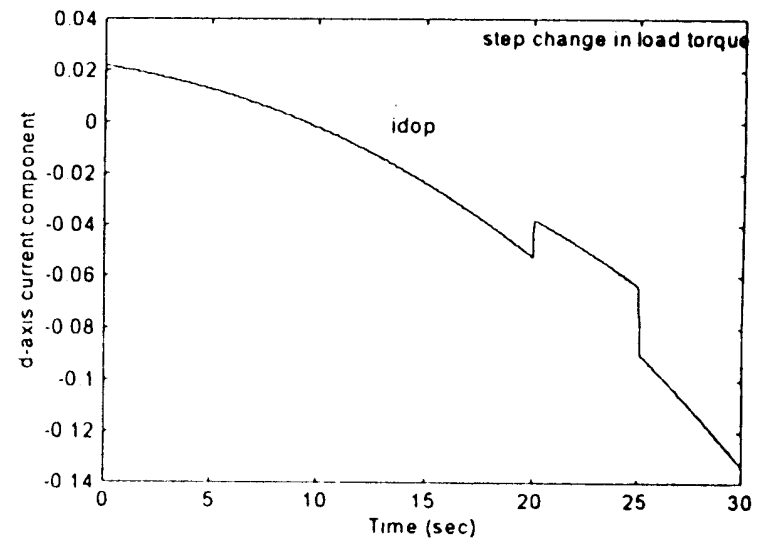

Fig.(8) NNS Output at Step Change in Load Torque

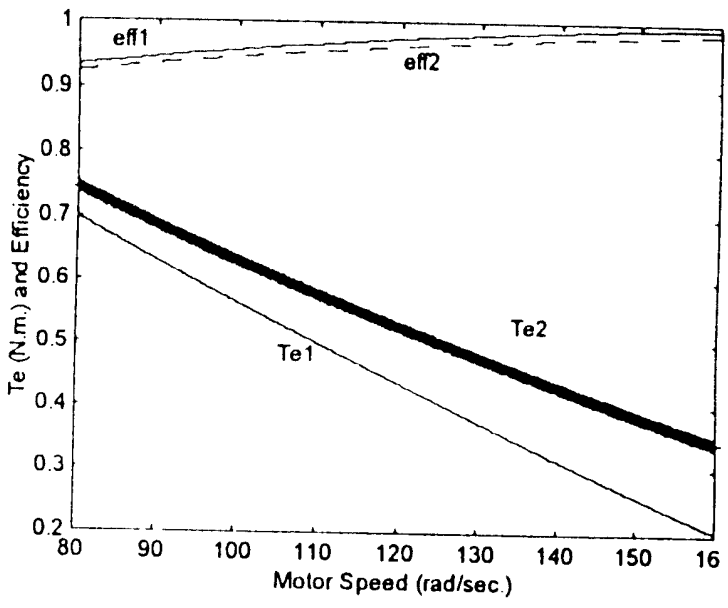

Fig. ( 10 ) Tel and effl Te at Zero Angle of Advance and $\mathrm{Te} 2$ and eff $2 \phi_{\text {op }}$ Operation

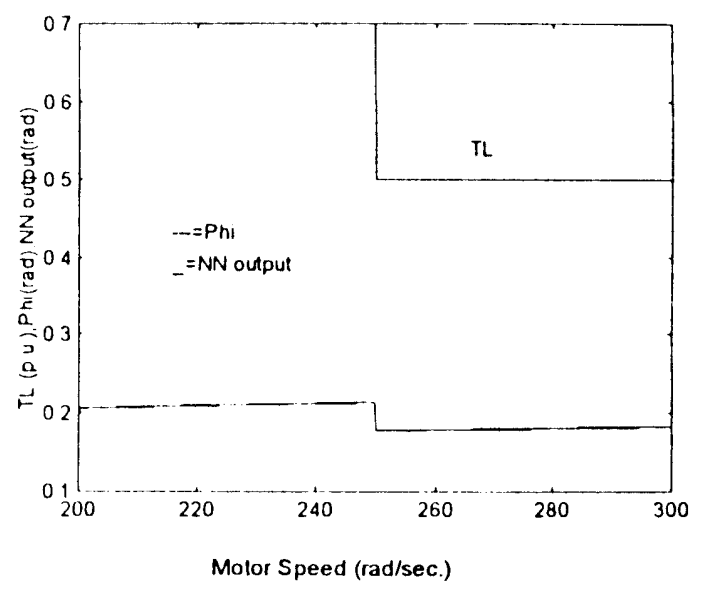

Fig.(12) Performance of NNA at Step Change in Load Torque 